\title{
Antimicrobial effect of ozonated water, sodium hypochlorite and chlorhexidine gluconate in primary molar root canals
}

\author{
Zeynep Goztas ${ }^{1}$, Halenur Onat ${ }^{2}$, Gul Tosun ${ }^{3}$, Yagmur Sener ${ }^{4}$, Hasan Huseyin Hadimli ${ }^{5}$
}

Correspondence: Halenur Onat

Email: onat_2012@windowslive.com

\author{
'Department of Pediatric Dentistry, Gazi University, \\ Ankara, Turkiye, \\ ${ }^{2}$ Department of Pediatric Dentistry, Mustafa Kemal \\ University, Hatay, Turkiye, \\ ${ }^{3}$ Department of Pediatric Dentistry, Selcuk University, \\ Konya, Turkiye, \\ ${ }^{4}$ Department of Pediatric Dentistry, Necmettin Erbakan \\ University, Konya, Turkiye, \\ ${ }^{5}$ Department of Veterinary, Selcuk University, Konya, \\ Turkiye
}

\section{ABSTRACT}

Objective: The aim was to determine the antimicrobial effect of ozonated water, ozonated water with ultrasonication, sodium hypochloride and chlorhexidine (CHX) in human primary root canals contaminated by Enterococcus faecalis (E. faecalis). Materials and Methods: Fifty-eight extracted human primary molar teeth were used. Crowns were cut off using a diamond saw under water-cooling. One hundred roots were obtained and mechanically prepared. The roots were then sterilized by autoclaving in water for $15 \mathrm{~min}$ at $121^{\circ} \mathrm{C}$. All samples were contaminated with E. faecalis for $24 \mathrm{~h}$ and the root canals were randomly divided into five groups $(n=20)$. Group I: $25 \mathrm{mg} / \mathrm{L}$ of Ozonated water $\left(\mathrm{O}_{3} \mathrm{aq}\right)$, Group II: $25 \mathrm{mg} / \mathrm{L}$ of $\mathrm{O}_{3}$ aq with ultrasonication, Group III: 2.5\% Sodium hypochloride (NaOCl), Group IV: 2\% CHX and Group V: Positive control. The canal of each specimen was irrigated for $4 \mathrm{~min}$ and positive control was untreated. All root canals were agitated with sterile saline solution. The saline solution was collected from canals with sterile paper points. For each specimen, the paper points were transposed to eppendorf vials containing $2 \mathrm{ml}$ of brain heart infusion. According to bacterial proliferation, the mean values of optical density were achieved by ELISA (Biotek EL $\times 800$, Absorbance Microplate Reader, ABD) and the data were analyzed. Results: NaOCI, $\mathrm{CHX}$ and two types of $\mathrm{O}_{3}$ aq were found statistically different than positive control group. NaOCI irrigation was found significantly most effective. Conclusions: $\mathrm{NaOCl}, \mathrm{CHX}$ and $\mathrm{O}_{3}$ aq applications provide antibacterial effect in vitro conditions in primary root canals.

Key words: Antibacterial agent, primary teeth, root canal irrigants

\section{INTRODUCTION}

Bacteria are the first etiologic factor in the growth of pulp and periapical diseases. If the microorganisms that are remained in the dentinal tubules are not completely eliminated, it may reinfect the root canal. Achieving a suitable environment for periapical lesion recovering and successful root canal treatment based on thorough chemo mechanical debriment of pulpal tissue, dentin debris and elimination of infective microorganisms. ${ }^{[1]}$ Antimicrobial solutions should have the capability to diffuse the infected location, to prevent or terminate microbial development and also possessing ability to dissolve organic material during endodontic treatment. ${ }^{[2]}$ Chemical debridement is particularly required for teeth with complex inner anatomy such as fins or other abnormality that may be skipped by instrumentation. ${ }^{[3]}$

\footnotetext{
How to cite this article: Goztas Z, Onat H, Tosun G, Sener Y, Hadimli HH. Antimicrobial effect of ozonated water, sodium hypochlorite and chlorhexidine gluconate in primary molar root canals. Eur J Dent 2014;8:469-74.

Copyright @ 2014 Dental Investigations Society. DOI: $10.4103 / 1305-7456.143627$
} 
Enterococcus faecalis (E. faecalis), which is one of the microorganisms resists against antimicrobial properties of calcium hydroxide, is entirely resistant to intracanal medicaments. ${ }^{[4]}$ Furthermore, E. faecalis has the substantial capability to diffuse the dentinal tubules, ${ }^{[5]}$ exhibits powerful adhesion to collagen, ${ }^{[6]}$ and presents defiance to irrigation solutions commonly used during the instrumentation of root canals.

$\mathrm{NaOCl}$ demonstrate effective antimicrobial movement, is a distinguished necrotic tissue solvent, and is the most productive irrigant in removing organic wreck from the root canal system. ${ }^{[7]}$ Chlorhexidine (CHX) can be considered as an alternative irrigation agent because of its substantivity. $\mathrm{CHX}$ has been utilized as an irrigant and intracanal medicament in endodontics. Ozonated water is known as a strong antimicrobial agent towards bacteria, fungi, viruses and protozoa. ${ }^{[8]}$ With an antimicrobial action, use of ozone is confirmed as a new alternative of irrigating agent with antimicrobial action..$^{[9]}$ Ozone in the aqueous phase has advantages that are its potency, lack of mutagenicity, rapid microbicidal effects, ease of handling and suitability for use as a soaking solution for dental and medical devices. ${ }^{[10]}$ Aqueous ozone presents no cytotoxicity and is highly biocompatible compared with other antiseptics. ${ }^{[11]}$ In addition, sodium hypochlorite is not as biocompatible as ozone in the aqueous phase for human oral epithelial cells, periodontal cells and gingival fibroblast cells. ${ }^{[11]}$

Maintaining the integrity of primary dentition is the most significant aspect of preventive dentistry. It is important to preserve the primary dentition until its normal exfoliation time as it basic for the development of facial-skeletal system. Dental decay is one of the general causes for the early loss of primary teeth. An option to avoid tooth loss would be an endodontic treatment, in which the main goal is to preserve the teeth in the same place. ${ }^{[12]}$ The reason for testing different irrigation solution on primary teeth in this study is that they have already been recognized as efficient for permanent teeth in the literature, and their effects on primary teeth are not widely known. In addition, as is known ozonated water has not been studied as endodontic irrigation agent for deciduous teeth.

The aim of this study was to compare the effectivity of two types of $\mathrm{O}_{3}$ aq, $\mathrm{NaOCl}$ and $\mathrm{CHX}$ as irrigant agent in the elimination of $E$. faecalis in primary molar root canals.

\section{MATERIALS AND METHODS}

\section{Tooth preparation}

The study sample comprised of 45 primary molars extracted due to infection or excessive caries that have radiographically visible no $>1 / 3$ physiological or pathological root resorption. Then, root surfaces were cleaned using a curette. Crowns of the teeth were removed to cemento-enamel junction by a diamond saw (Isomet; Buehler, USA) with water-cooling and 80 roots were obtained. An access cavity orifice was processed, and the pulpal tissue was removed by using a barbed broach (Antaeos, VDW GmbH, Germany) and the root canals were enlarged to a size 30 (blue number 04 taper) using rotary instruments (Hero 642; MicroMega, France). In the course of instrumentation, all root canals were irrigated with $5 \% \mathrm{NaOCI}$ at each file used. Afterwards initial preparation, the smear layer of each sample was removed in an ultrasonic bath (USG 4000 Ultraschall, Dentaurum, Germany) with 17\% ethylenediaminetetraacetic acid (pH7.8) and 5\% NaOCl for $10 \mathrm{~min}$. After the roots were dried by using sterile paper points (Dentsply, RJ, Brazil), the apical foramina were covered using flowable composite resin (Filtek Supreme XT, 3MEspe, USA) and the root canals were immersed in acrylic resin blocks (Zetaplus, Zhermack SpA, Italya), which allowed handling of the teeth during the experiment. The samples were autoclaved for $15 \mathrm{~min}$ at $121^{\circ} \mathrm{C}$. The blocks were kept in sterile water to avoid dehydration until use. After this stage, all samples were operated using rigid aseptic protocols.

\section{Contamination of root canals}

A total sum of 80 root canals was inoculated by E. faecalis (ATCC 29212) for $24 \mathrm{~h}$. The bacterial sample was inoculated on brain heart infusion (BHI) broth (Difco, Detroit, MI) then incubated aerobically for $24 \mathrm{~h}$ at $37^{\circ} \mathrm{C}$. Bacterial cells were resuspended in saline to give a final concentration of about $1.5 \times 10^{8}$ colony forming units per $\mathrm{ml}\left(\mathrm{CFU}^{-1}\right)$, and the turbidity of E. faecalis culture was adjusted to No. 0.5 McFarland standards.

Prepared samples were dried using sterile paper points in lamin airflow chamber. With a sterile micropipette, $5 \mu \mathrm{l}$ of bacterial suspension was used into the enlarged root canals. All specimens were kept for $24 \mathrm{~h}$ at $37^{\circ} \mathrm{C}$ under aerobic conditions.

\section{Disinfection procedures}

The samples were randomly separated into four experimental groups $(n=20)$. The canal of each specimen was irrigated for 4 min with the $5 \mathrm{ml}$ of following solutions: $25 \mathrm{mg} / \mathrm{L}$ of ozonated water $\left(\mathrm{O}_{3} \mathrm{aq}\right)$, 
$2.5 \% \mathrm{NaOCl}$ and $2 \% \mathrm{CHX}$. One group as a positive control was not irrigated $(n=20)$. After the disinfection procedures, the root canals in total groups were rinsed by using $1 \mathrm{ml}$ of sterile saline solution. The saline solution was collected from canals with a standard 15 size sterile paper points for sample collection for $1 \mathrm{~min}$. The paper points were transposed to eppendorf vials having $200 \mu \mathrm{l}$ of $\mathrm{BHI}$ broth. All collected samples were agitated on a vortex mixer for $5 \mathrm{~min}$.

Microbial analysis was performed with spectrometer. The optic density (OD) of the broth is directly related to the number of bacteria present and can be used to examine the antimicrobial efficacy of a medication. $20 \mu \mathrm{l}$ suspensions were transferred on the sterile 96-well plates, and the first measurements were performed $(0 \mathrm{~h})$ and were repeated (at 6, 12, 24 and $48 \mathrm{~h}$ ) during incubation at $37^{\circ} \mathrm{C}$. This process was repeated 3 times.

\section{Statistical analysis}

The spectrophotometric results were analyzed using one-way ANOVA and Tukey $t$-tests. The mean difference is significant at the 0.05 level, and $P<0.05$ was considered to be statistically different.

\section{RESULTS}

The means of OD values are presented in Figure 1. Figure 1 shows the antimicrobial effectiveness of the solutions as irrigants. The untreated positive control group revealed the highest mean of OD values in all measurements. According to comparison of the groups in pairs the first measurement $(0 \mathrm{~h})$ showed that $\mathrm{O}_{3}$ aq $(P=0.034)$ and $\mathrm{CHX}(P=0.00)$ had more antibacterial activity than the control group. The second measurement $(6 \mathrm{~h})$ showed that CHX had lower OD values, but the difference was not statistically significant between $\mathrm{CHX}$ and $\mathrm{NaOCl}$. There was no difference between $\mathrm{NaOCl}$ and $\mathrm{O}_{3}$ aq in first and second measurements $(0,6 \mathrm{~h})$. According

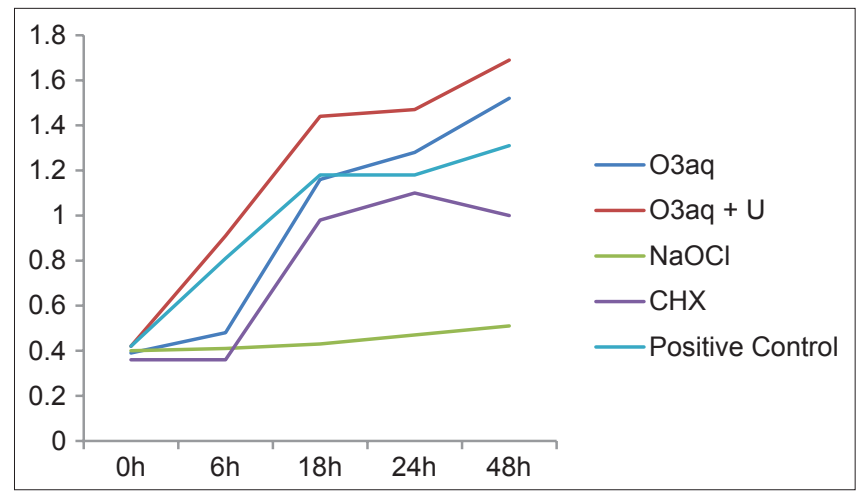

Figure 1: The means of optical density values to the measurements at other intervals $(18,24,48 \mathrm{~h})$, $\mathrm{NaOCl}$ appeared to be the most effective irrigant on E. faecalis. Antibacterial efficacy of $\mathrm{NaOCl}$ was stable over $48 \mathrm{~h}$ test period progressive increase was observed for OD values for all four experimental groups depending on the time.

\section{DISCUSSION}

In endodontic treatment, major goal is to disinfect the root canal system before canal obturation. ${ }^{[13]}$ Residual tissue in the root canal may supply enough sustenance for bacteria. ${ }^{[2]}$ Irrigation procedures with antimicrobial agents allow disinfection of places of the root canal system, which is unreachable by instrumentation. ${ }^{[14]}$ Antimicrobial irrigating agents must have plenty qualities like the ability to diffuse the infected place, to terminate microbial growth as well as possessing the ability to dissolve organic material, and to avoid the potential growth of resistance to the solutions. ${ }^{[2]}$

Deciduous teeth may present unusual internal morphology of the pulp chamber, such as connections, including horizontal anastomoses and furcation, presence of inaccessible areas. Therefore, endodontic treatment of primary teeth is considered extremely sophisticated. In the root canal system with such a complicated and active microbial circumference, choice of an efficacious antibacterial agent is critical during treatment. ${ }^{[2,3]}$ This in vitro study was designed to highlight the efficacy of $\mathrm{O}_{3}$ aq, $\mathrm{CHX}$ and $\mathrm{NaOCl}$ in the endodontic therapies of primary molars, and determine whether they can be suggested as an irrigation agent.

Infections in primary root canal are associated with a broad variety of microorganisms. Cogulu et al. ${ }^{[15]}$ found that the most prevalent species of bacteria in deciduous root canal were E. faecalis, Porphyromonas gingivalis and Treponema denticola. In this study was selected E. faecalis, because it is a Gram-positive facultative anaerobic coccus, which is a well-known endodontic pathogen, for the infection of the root canals.

The depth of penetration of microorganisms affected different factors; one of these factors is the incubation time. ${ }^{[16]}$ It was reported that E. faecalis achieves $300-400 \mu \mathrm{m}$ in dentine channels within $24 \mathrm{~h}$, and it was shown that no difference between bacterial penetrations of dentine channels with much more than incubation time. ${ }^{[17]}$ Haapasalo and Orstavik ${ }^{[17]}$ recommended that shorter incubation times can use experimental studies. In an in vitro study of Behnen et al. ${ }^{[18]}$ samples were incubated for $24 \mathrm{~h}$ with E. faecalis 
and they reported that this period is sufficient to infect dentinal tubules. In the present study, $24 \mathrm{~h}$ incubation time was selected to infect primary molar root canals according to Behnen et al..$^{[18]}$

It has been advocated use $\mathrm{NaOCl}$ in concentrations ranging from $0.5 \%$ to $5.25 \%$, but there has been no agreement on the optimal concentration. Baumgartner and Mader ${ }^{[19]}$ confirmed that $2.5 \% \mathrm{NaOCl}$ is extremely effective in removing vital pulp tissue from dentinal walls. Siqueira et al. ${ }^{[14]}$ reported that using $\mathrm{NaOCI}$ in $2.5 \%$ concentrations may significantly reduce the endodontic infection, but might not consistently dissolve all pulpal remnants in a reasonable time. Some authors emphasized that the antibacterial effectiveness of $2.5 \%$ concentrations of $\mathrm{NaOCI}$ might be improved by usage larger volumes of solution and continuous exchange of agent. ${ }^{[14]}$ Siqueira et al..$^{[14]}$ reported that instrumentation and irrigation by using $2.5 \% \mathrm{NaOCl}$ provided a decrease of $99.9 \%$ in the count of viable bacteria in the root canal.

Although $\mathrm{NaOCl}$ has become the well-known popular irrigation agent for endodontic usage, it may cause rather toxic damage to the periapical environment if passes through the tooth apical foramina.${ }^{[3]}$ Nontoxicity to periapical tissues is an important requirement of endodontic irrigants, especially in pediatric patients. In primary teeth, overflow of irrigating solution through the apical region because of possible resorption areas could damage the underlying permanent tooth. The cytotoxicity of $5.25 \% \mathrm{NaOCl}$ toward periapical tissues has been stated in the case reports. ${ }^{[9]}$ Hence, 2.5\% $\mathrm{NaOCI}$ was chosen for appropriate concentration at primary teeth root canal treatment.

We prepared in vitro infected model to evaluate antibacterial efficacy of $25 \mathrm{mg} / \mathrm{L}$ of $\mathrm{O}_{3}$ aq, $2 \% \mathrm{CHX}$ solutions as well as $2.5 \%$ NaOCI's as endodontic irrigants and we set 4 min contact time for this investigation. After irrigation step, no neutralizing agent was used to reduce the carry-over effect the disinfectant solutions because of a lack of any "universal" neutralized agent appropriate for all the disinfectants which were tested. ${ }^{[20]}$ Some of the previously suggested neutralizing agents such as sodium thiosulfate for $\mathrm{NaOCI}$, Tween 80 and Lecitin combinations for $\mathrm{CHX}$ in different ratios, have various antimicrobial effects, which might also deteriorate the results, and therefore, all groups were tested under same conditions in this study. ${ }^{[20]}$

In first $6 \mathrm{~h}, \mathrm{CHX}$ was found to be the most effective as an irrigant. It was, followed by $\mathrm{O}_{3}$ aq and $\mathrm{NaOCl}$ respectively which showed similar antimicrobial effectiveness. These results are in accordance with the result of some other investigators. Onçag et al. ${ }^{[21]}$ reported that after the irrigation procedures, $5 \mathrm{~min}$ $2 \% \mathrm{CHX}$ had a faster and more effective on E. faecalis compared $\mathrm{NaOCl}$. Vianna et al. ${ }^{[22]}$ compared that $2 \%$ $\mathrm{CHX}$ and $2.5 \% \mathrm{NaOCl}$ in vitro, and demonstrated that $2 \% \mathrm{CHX}$ was more efficient to inhibition of growth of E. faecalis, Staphylococcus aureus and Candida albicans. Jeansonne and White ${ }^{[23]}$ compared the antibacterial effect of different irrigation solutions against anaerobic bacteria and noticed that $2 \% \mathrm{CHX}$ was more effective than $5.25 \% \mathrm{NaOCI}$, but the differences were not statistically significant.

White et al. ${ }^{[13]}$ claimed that, after instrumentation, $\mathrm{CHX}$ continues to be released while $48-72 \mathrm{~h}$. CHX and $\mathrm{O}_{3}$ aq preserved antibacterial effect respectively 24 and $18 \mathrm{~h}$. The stability of antibacterial efficacy of endodontic irrigants, especially in prolonged periods of treatment, is very important. It was concluded that $\mathrm{NaOCl}$ should remain in the root canal for a considerable time, so that it can act on the residual bacteria placed in the irregularities in the root canal. ${ }^{[21]}$

Some researchers claimed that $\mathrm{CHX}$ and $\mathrm{O}_{3}$ aq appear to be an effective, and possibly preferential, alternate to $\mathrm{NaOCl}$ with respect to antimicrobial activity and less toxicity. Huth et al. ${ }^{[2]}$ reported that $\mathrm{O}_{3}$ aq had the maximum grade of biocompatibility of the tested antiseptics $(5.25 \%$ and $2.25 \% \mathrm{NaOCl}, 2 \%$ and $0.2 \%$ CHX, 3\% hydrogen peroxide $\left(\mathrm{H}_{2} \mathrm{O}_{2}\right)$. Jeansonne and White ${ }^{[23]}$ concluded that $2 \% \mathrm{CHX}$ had similar antibacterial effectiveness to $5.25 \% \mathrm{NaOCl}$, and for its lower toxicity, CHX should be preferential in endodontic therapy of the teeth with open apices.

The findings of this study demonstrate that $2 \% \mathrm{CHX}$ showed antibacterial activity for $24 \mathrm{~h}$ in the primary teeth root canals. Ruiz-Esparza et al. ${ }^{[25]}$ reported that $2 \%$ CHX showed a greater reduction of intracanal bacterial loading and suggested that this irrigating solution is an alternative for pulpectomy treatment of necrotic primary teeth. Leonardo et al. ${ }^{[26]}$ concluded that $\mathrm{CHX}$ gluconate has been recommended as an irrigation solution because of its antibacterial effectiveness, substantivity and lower cytotoxicity compared with $\mathrm{NaOCl}$. On the other hand, just a few investigations have studied the antimicrobial effectiveness of $\mathrm{CHX}$ as an irrigation solution in primary root canals. In order to confirm these results, it will be necessary to carry out in vitro and in vivo studies.

European Journal of Dentistry, Vol 8 / Issue 4 / Oct-Dec 2014 
The ozone $\left(\mathrm{O}_{3}\right)$ produced by an electrical discharge on high-purity oxygen molecules with a generator developed at Water Tech Solutions Co., Ltd., USA, was used. Since gaseous ozone has been established to get toxic action if inhaled into the respiratory system, therefore, ozonated water might be beneficial to management oral infections and varied pathogens. ${ }^{[27]}$ Gaining ozone in water was made by bubbling ozone thru sterile distilled water $\left(\mathrm{O}_{3}\right.$ concentration $\left.24 \mathrm{mg} / \mathrm{L}\right)$. The selection of the ozonated water concentration $(24 \mathrm{mg} / \mathrm{L})$ was according to the higher concentration, which the generator can produce. ${ }^{[1]}$ Ozonated water usage for therapy of endodontic infections has been recommended. ${ }^{[28,29]}$ Nagayoshi et al. ${ }^{[28]}$ concluded that ozonated water had almost the equal antimicrobial effectiveness as $2.5 \%$ $\mathrm{NaOCl}$ for endodontic irrigation. They also showed that a lower grade of toxicity against bacterial cells. On the other hand, Hems et al. ${ }^{[29]}$ evaluating the capability of ozone to terminate an E. faecalis strain confirmed that its antibacterial effectiveness was not comparable to $\mathrm{NaOCl}$. Among the current irrigating solutions, ozone has some interesting features; debriding action, bactericidal effect, angiogenesis stimulation capability and high oxidizing power. In addition, as far as we know, ozonated water has not been studied as endodontic irrigation agent in primary teeth.

In our study, $\mathrm{O}_{3}$ aq was effective compared with positive control in $6 \mathrm{~h}$; however following measurements that were performed at other times $(18,24$ and $48 \mathrm{~h}$ ) showed that $\mathrm{O}_{3}$ aq groups' antimicrobial effectiveness decreased rapidly compared with other groups [Figure 1]. We concluded that the ozonated water had no residual effect during the study. This may be correlated to poor diffusion ability of these substances to deeper areas of the dentinal tubules. Also, irregularity of primary root canal system may have restrained antibacterial activity of ozonated water. Rapid deterioration of the ozone just after contact with organic compounds, such as culture media, which is one of its environmental disadvantages, may cause a decrease in antimicrobial effectiveness of ozonated water. Furthermore, Cardoso et al. ${ }^{[1]}$ reported that the ozonated water was efficient against $E$. faecalis and $C$. albicans but had no remaining effect. Nagayoshi et al.$^{[28]}$ reported that after irrigation with $\mathrm{O}_{3}$ aq, the viability of Streptococcus mutans and E. faecalis, invading dentinal tubules significantly reduced. Haas and Kaymak ${ }^{[30]}$ reported that the antimicrobial effect of ozone depends on varied factors, such as ozone concentration and quantity of bacteria, exposure period, and variables in the bacterial permeability that verified the occurrence of diverse effects on each microorganism.
Several questions about the effectiveness of ozone on endodontic microbiota, such as the optimum concentration, its deepness of action in dentinal tubules and the ideal time to achieve total antimicrobial effect, remain unclear. ${ }^{[9]}$ Additional studies are needed to evaluate antibacterial effectiveness of endodontic irrigants in different clinical situations especially in primary root canals.

\section{CONCLUSION}

Within the limitations of this study, we concluded that the tested solutions showed antibacterial activity. Due to aqueous ozone that demonstrates no citotoxicity and high biocompatibly can be used as primary root canal irrigation agent for especially pediatric patient. $\mathrm{CHX}$ can be considered as an alternative irrigation agent instead of $\mathrm{NaOCI}$ because of substantivity.

\section{REFERENCES}

1. Cardoso MG, de Oliveira LD, Koga-Ito CY, Jorge AO. Effectiveness of ozonated water on Candida albicans, Enterococcus faecalis, and endotoxins in root canals. Oral Surg Oral Med Oral Pathol Oral Radiol Endod 2008;105:e85-91.

2. Carson KR, Goodell GG, McClanahan SB. Comparison of the antimicrobial activity of six irrigants on primary endodontic pathogens. J Endod 2005;31:471-3.

3. Ahangari Z, Samiee M, Yolmeh MA, Eslami G. Antimicrobial activity of three root canal irrigants on enterococcus faecalis: an in vitro study. Iran Endod J 2008;3:33-7.

4. Sundqvist G. Taxonomy, ecology, and pathogenicity of the root canal flora. Oral Surg Oral Med Oral Pathol 1994;78:522-30.

5. Sunde PT, Olsen I, Debelian GJ, Tronstad L. Microbiota of periapical lesions refractory to endodontic therapy. J Endod 2002;28:304-10.

6. Love RM. Enterococcus faecalis - A mechanism for its role in endodontic failure. Int Endod J 2001;34:399-405.

7. Harrison JW. Irrigation of the root canal system. Dent Clin North Am 1984;28:797-808.

8. Kim JG, Yousef AE, Dave S. Application of ozone for enhancing the microbiological safety and quality of foods: a review. J Food Prot 1999;62:1071-87.

9. Estrela C, Estrela CR, Decurcio DA, Hollanda AC, Silva JA. Antimicrobial efficacy of ozonated water, gaseous ozone, sodium hypochlorite and chlorhexidine in infected human root canals. Int Endod J 2007;40:85-93.

10. Restaino L, Frampton EW, Hemphill JB, Palnikar P. Efficacy of ozonated water against various food-related microorganisms. Appl Environ Microbiol 1995;61:3471-5.

11. Lynch E, Goldstep F, Freedman G. Contemporary Esthetic Dentistry, Technology and Esthetics. Elsevier, St. Louis, Missouri: Mosby Publishing; 2011. p. 597.

12. Hariharan VS, Nandlal B, Srilatha KT. Efficacy of various root canal irrigants on removal of smear layer in the primary root canals after hand instrumentation: a scanning electron microscopy study. J Indian Soc Pedod Prev Dent 2010;28:271-7.

13. White RR, Hays GL, Janer LR. Residual antimicrobial activity after canal irrigation with chlorhexidine. J Endod 1997;23:229-31.

14. Siqueira JF Jr, Rôças IN, Favieri A, Lima KC. Chemomechanical reduction of the bacterial population in the root canal after instrumentation and irrigation with $1 \%, 2.5 \%$, and $5.25 \%$ sodium hypochlorite. J Endod 2000;26:331-4.

15. Cogulu D, Uzel A, Oncag O, Eronat C. PCR-based identification of selected pathogens associated with endodontic infections in deciduous and permanent teeth. Oral Surg Oral Med Oral Pathol Oral Radiol Endod 2008;106:443-9. 
16. Peters LB, Wesselink PR, Moorer WR. Penetration of bacteria in bovine root dentine in vitro. Int Endod J 2000;33:28-36.

17. Haapasalo M, Orstavik D. In vitro infection and disinfection of dentinal tubules. J Dent Res 1987;66:1375-9.

18. Behnen MJ, West LA, Liewehr FR, Buxton TB, McPherson JC $3^{\text {rd }}$. Antimicrobial activity of several calcium hydroxide preparations in root canal dentin. J Endod 2001;27:765-7.

19. Baumgartner JC, Mader CL. A scanning electron microscopic evaluation of four root canal irrigation regimens. J Endod 1987;13:147-57.

20. Eldeniz AU, Guneser MB, Akbulut MB. Comparative antifungal efficacy of light-activated disinfection and octenidine hydrochloride with contemporary endodontic irrigants. Lasers Med Sci 2013.

21. Onçag O, Hosgör M, Hilmioglu S, Zekioglu O, Eronat C, Burhanoglu D. Comparison of antibacterial and toxic effects of various root canal irrigants. Int Endod J 2003;36:423-32.

22. Vianna ME, Gomes BP, Berber VB, Zaia AA, Ferraz CC, de Souza-Filho FJ. In vitro evaluation of the antimicrobial activity of chlorhexidine and sodium hypochlorite. Oral Surg Oral Med Oral Pathol Oral Radiol Endod 2004;97:79-84.

23. Jeansonne MJ, White RR. A comparison of $2.0 \%$ chlorhexidine gluconate and $5.25 \%$ sodium hypochlorite as antimicrobial endodontic irrigants. J Endod 1994;20:276-8.

24. Huth KC, Jakob FM, Saugel B, Cappello C, Paschos E, Hollweck R, et al. Effect of ozone on oral cells compared with established antimicrobials. Eur J Oral Sci 2006;114:435-40.

25. Ruiz-Esparza CL, Garrocho-Rangel A, Gonzalez-Amaro AM, Flores-Reyes H, Pozos-Guillen AJ. Reduction in bacterial loading using
$2 \%$ chlorhexidine gluconate as an irrigant in pulpectomized primary teeth: A preliminary report. J Clin Pediatr Dent 2011;35:265-70.

26. Leonardo MR, Tanomaru Filho M, Silva LA, Nelson Filho P, Bonifácio $\mathrm{KC}$, Ito IY. In vivo antimicrobial activity of $2 \%$ chlorhexidine used as a root canal irrigating solution. J Endod 1999;25:167-71.

27. Loncar B, Mravak Stipetic M, Matosevic D, Tarle Z. Ozone application in dentistry. Arch Med Res 2009;40:136-7.

28. Nagayoshi M, Kitamura C, Fukuizumi T, Nishihara T, Terashita M. Antimicrobial effect of ozonated water on bacteria invading dentinal tubules. J Endod 2004;30:778-81.

29. Hems RS, Gulabivala K, Ng YL, Ready D, Spratt DA. An in vitro evaluation of the ability of ozone to kill a strain of Enterococcus faecalis. Int Endod J 2005;38:22-9.

30. Haas CN, Kaymak B. Effect of initial microbial density on inactivation of Giardia muris by ozone. Water Res 2003;37:2980-8.

\begin{tabular}{|l|l|}
\hline \multicolumn{2}{|c|}{ Access this article online } \\
\hline Quick Response Code: & Website: \\
\hline & www.eurjdent.com \\
\cline { 2 - 3 } & \\
\hline
\end{tabular}

